\title{
Fed-batch fermentation of olive mill wastewaters for lipase production
}

\section{Cristiana Gonçalves, Felisbela Oliveira, Carina Pereira and Isabel Belo*}

\begin{abstract}
In the Mediterranean basin countries, huge amounts of olive mill wastewaters (OMW) are produced by the olive oil industry. It constitutes a serious environmental problem, nevertheless its composition turns OMW into a potential growth medium to lipolytic microorganisms. The aim of this work was to study lipase production as well as OMW degradation in fed-batch cultures of Candida cylindracea CBS 7869, Candida rugosa CBS 2275 and Yarrowia lipolytica W29 (ATCC 20460). Besides the improvement of lipase production, the fed-batch approach enhanced the effluent degradation, since it led to good COD and lipids reduction, both higher than $50 \%$. C. rugosa achieved the highest value of lipase productivity $\left(130 \mathrm{U} \mathrm{L}^{-1} \mathrm{~h}^{-1}\right)$, in parallel with highest lipids reduction $(\mathbf{7 7 \% )}$. This study demonstrates that $\mathrm{OMW}$ are becoming a competitive and valuable growth medium in fermentation processes with lipolytic microorganisms. The fed-batch strategy used proved to be an efficient approach to enhance lipase production from OMW and to reduce significantly the final organic load of the medium.

(c) 2012 Society of Chemical Industry
\end{abstract}

Keywords: Candida species; Yarrowia lipolytica; lipase; olive mill wastewater; fed-batch fermentation

\section{INTRODUCTION}

Olive oil is one of the most important elements in the traditional Mediterranean diet. Mediterranean countries are known to have favourable conditions for olive oil production. Spain, Italy and Greece are the most significant olive oil producers with $47 \%$, $16 \%$ and $11 \%$ of the $2009 / 2010$ world's production, respectively. Portugal was responsible for $2 \%$ (58700 tonnes) of the world's production in 2009/2010, and 67500 tonnes were expected for 2010/2011. ${ }^{1}$ Huge amounts of olive mill wastewaters (OMW) are produced; typically, reaching $1.3 \mathrm{~m}^{3}$ of OMW per ton of olives processed. $^{2}$ The OMW content of simple and complex sugars, residual oil (lipids), proteins, mineral elements and phenols, turns this effluent into a renewable resource, as its components can be extracted and purified or used for fermentative production processes. ${ }^{3-5}$ In addition, residual oil in OMW turns this waste into a potential growth medium for lipolytic microorganisms. ${ }^{2,6}$ Although the use of OMW as a growth medium to produce lipase has been studied by several authors, $2,4,5,7,8$ it has been mostly conducted using batch operation, even though many reports revealed that, with synthetic media, the highest lipase production was achieved with a fed-batch strategy. ${ }^{9-11}$

The aim of this work was to study the performance of three yeast species in fed-batch cultures using OMW-based medium, with the purpose of optimizing lipase (EC 3.1.1.3) production as well as OMW degradation. Batch cultures were performed as comparison.

\section{MATERIALS AND METHODS Microorganisms}

Candida cylindracea CBS 7869, Candida rugosa CBS 2275 and Yarrowia lipolytica W29 (ATCC 20 460) were maintained in YPDA plates ( $10 \mathrm{~g} \mathrm{~L}^{-1}$ yeast extract, $20 \mathrm{~g} \mathrm{~L}^{-1}$ peptone, $20 \mathrm{~g} \mathrm{~L}^{-1}$ glucose, $30 \mathrm{~g} \mathrm{~L}^{-1}$ agar) at $4{ }^{\circ} \mathrm{C}$. Cells were pre-grown in YPD medium
(10 $\mathrm{g} \mathrm{L}^{-1}$ yeast extract, $20 \mathrm{~g} \mathrm{~L}^{-1}$ peptone and $20 \mathrm{~g} \mathrm{~L}^{-1}$ glucose), before being used for the OMW medium inoculation.

Olive mill wastewater

OMW samples were collected from three-phase olive oil mills in the northern region of Portugal, during the olive oil production campaign of $2009 / 2010$. They were stored at $-20^{\circ} \mathrm{C}$, on the same day of collection.

OMW was characterized in terms of $\mathrm{pH}$, chemical oxygen demand (COD), total nitrogen (TN), total organic carbon (TOC), total solids (TS), total volatile solids (TVS), total suspended solids (TSS), reducing sugars, total phenols, total lipids and long chain fatty acids (LCFA). The characterization of raw OMW is shown in Table 1. The main free LCFA present in the OMW collected were palmitic acid (C16:0), palmitoleic acid (C16:1), stearic acid (C18:0) and oleic acid (C18:1). COD, TN and TOC were determined using test kits (Hach Lange). Solids (total, volatile and dissolved) were assessed according to standard methods. ${ }^{12}$ Total phenols and reducing sugars were assessed by the Folin-Ciocalteau method (Commission Regulation (EEC) No. 2676/90) and by a DNS-adapted method, respectively. ${ }^{13}$ LCFA were determined as described elsewhere. ${ }^{14}$ Lipids (total fat) content was extracted with diethyl ether, in a Soxtec System HT2 1045-extraction unit, after samples lyophilization. ${ }^{15}$ 


\begin{tabular}{|c|c|c|}
\hline Parameter & & Value \\
\hline $\mathrm{pH}$ & & 4.5 \\
\hline $\mathrm{COD} /\left(\mathrm{g} \mathrm{L}^{-1}\right)$ & & $261 \pm 25$ \\
\hline $\mathrm{TN} /\left(\mathrm{mg} \mathrm{L}^{-1}\right)$ & & $198 \pm 10$ \\
\hline $\mathrm{TOC} /\left(\mathrm{g} \mathrm{L}^{-1}\right)$ & & $45.6 \pm 0.0$ \\
\hline $\mathrm{TS} /\left(\mathrm{g} \mathrm{L}^{-1}\right)$ & & $155 \pm 1$ \\
\hline $\mathrm{TVS} /\left(\mathrm{g} \mathrm{L}^{-1}\right)$ & & $116 \pm 6$ \\
\hline $\mathrm{TSS} /\left(\mathrm{g} \mathrm{L}^{-1}\right)$ & & $55.4 \pm 8.8$ \\
\hline Reducing sugars/(g L L & & $68.5 \pm 1.18$ \\
\hline Phenols/(g L $\left.\mathrm{L}^{-1}\right)$ & & $7.9 \pm 1.9$ \\
\hline Lipids/(g L $\left.{ }^{-1}\right)$ & & $31.9 \pm 15.1$ \\
\hline \multirow[t]{4}{*}{$\mathrm{LCFA} /\left(\mathrm{mg} \mathrm{L}^{-1}\right)$} & C16:0 & $2446 \pm 120$ \\
\hline & $\mathrm{C} 16: 1$ & $N^{*}$ \\
\hline & C18:0 & $733 \pm 71$ \\
\hline & C18: 1 & $2390 \pm 76$ \\
\hline
\end{tabular}

\section{OMW-based medium}

The OMW-based medium is composed of OMW (Table 1), without dilution and supplemented with ammonium chloride, in order to obtain a $\mathrm{C} / \mathrm{N}$ ration of 15 ; and yeast extract, in a ratio of $2: 5$ relative to the $\mathrm{NH}_{4} \mathrm{Cl}$ added, to assure a minimum amount of vitamins. Before sterilization, the $\mathrm{pH}$ was adjusted to 7.2 , with $\mathrm{NaOH}$, and six drops of silicon antifoam agent were added.

\section{Batch and fed-batch trials}

Batch and fed-batch trials were performed in a $2 \mathrm{~L}$ bioreactor (Biolab, B. BRAUN) using the following conditions: $\mathrm{pH} 7.2$, aeration rate $1.5 \mathrm{~L} \mathrm{~min}^{-1}$ and agitation $500 \mathrm{rpm}$. $\mathrm{pH}$ was automatically adjusted with $\mathrm{NaOH} 1 \mathrm{~N}$ and $\mathrm{HCl} 1 \mathrm{~N}$. In batch experiments, the reactor was filled with $1.3 \mathrm{~L}$ of OMW-based medium after sterilization; it was inoculated with an amount of yeast cells, previously grown in YPD medium, to attain an initial cell concentration of $1 \times 10^{8}$ cells $\mathrm{mL}^{-1}$. Fed-batch experiments were initiated with a batch phase of $24 \mathrm{~h}$, after which OMWbased medium was used to feed the bioreactor. The feeding was performed with two pulses per day of $10 \%(\mathrm{v} / \mathrm{v})$ of the medium volume inside the reactor, each. Thus, fed-mode operation was approximated by a repeated-batch operation. The dilution rate was approximately $0.015 \mathrm{~h}^{-1}$. The fed-batch was stopped when the reactor was filled to $1.5 \mathrm{~L}$, with $1 \mathrm{~L}$ of OMW-based medium, achieving 9 days of fermentation. The cells were grown within the bioreactor (with $400 \mathrm{~mL}$ of YPD) and the OMW-based medium was fed afterwards.

The time course of cell density (determined by microscopic cell counting), total phenols, reducing sugars and lipase activity were followed throughout the experiments. However, chemical oxygen demand (COD), total nitrogen (TN) and total organic carbon (TOC) were assessed only at the beginning and the end point of the experiments.

\section{Enzymatic assays}

Extracellular lipase was measured in the samples supernatant, using $p$-nitrophenyl-butyrate ( $p$-NPB) in sodium acetate buffer $50 \mathrm{mmol} \mathrm{L}^{-1}$ (pH 5.6) as substrate, at $37^{\circ} \mathrm{C}$ for $15 \mathrm{~min}$. One unit of activity was defined as the amount of enzyme that produces
$1 \mu \mathrm{mol}$ of $p$-nitrophenol per minute, under assay conditions. ${ }^{16}$ Protease in cell-free samples was quantified using $0.5 \%(\mathrm{w} / \mathrm{v})$ azocasein as substrate in acetate buffer at $\mathrm{pH} 5.0,37^{\circ} \mathrm{C}$ for $40 \mathrm{~min}$. One unit of activity was defined as the amount of enzyme per minute that causes an increase of 0.01 of absorbance, relative to the blank, under assay conditions.

\section{RESULTS AND DISCUSSION}

The aim of this study was to investigate the performance of three yeast species in batch and fed-batch cultures in OMW-based medium, with the purpose of improving lipase production as well as OMW degradation. Figure 1 depicts the results obtained in batch mode experiments. All strains presented similar cellular growth profiles on OMW medium, showing a remarkable cell adaptation to the undiluted OMW, since no cellular growth inhibition was observed for the three strains. Reducing sugars consumption profiles were quite similar between strains and overall sugars degradation was 49\%, 43\% and 54\% for C. cylindracea, Y. lipolytica and C. rugosa, respectively. Most of this consumption (around $85 \%$ ) was achieved in the early hours, especially for C. cylindracea CBS 7869, which presented highest extracellular lipase productivity (30 U L $\left.\mathrm{L}^{-1} \mathrm{~h}^{-1}\right)$, compared with C. rugosa $\left(20 \mathrm{U} \mathrm{L}^{-1} \mathrm{~h}^{-1}\right)$ and $Y$. lipolytica $\left(7 \mathrm{UL}^{-1} \mathrm{~h}^{-1}\right)$. The sugar consumption profile is indicative of a short lag phase for all yeasts under study, which corroborates the good adaptability of these strains to OMW based medium. Brozzoli et al. ${ }^{2}$ also obtained highest initial rates of total sugars consumption by Candida cylindracea NRRL Y-17506, grown in a $3 \mathrm{~L}$ bench-top stirred tank reactor on OMW-based medium. In batch cultures of this study, C. cylindracea was the yeast with the best lipase productivity. Several authors had previously screened some yeast strains and other microorganisms for lipase production and $C$. cylindracea is often pointed out as the best lipase producer.,8 Regarding OMW degradation, other authors reported that $C O D$ concentration gradually decreases throughout the experiments, 3,7,19 however in the herein reported batch experiments, negligible COD degradation was obtained. In fact, the OMW used in this study presented an extremely high value of COD $\left(261 \mathrm{~g} \mathrm{~L}^{-1}\right)$ while other authors generally use OMW with COD values below $100 \mathrm{~g} \mathrm{~L}^{-1}$. 3,7,19,20,21 Although this concentration has not been toxic for the microorganisms, it did not allow COD degradation.

Other modes of operation have proven to be useful to increase lipase production in synthetic media. ${ }^{9-11}$ Montesinos et al. ${ }^{11}$ studied the interaction between medium components, microorganisms and the operational mode, to produce lipase by Candida rugosa ATCC 14830 in synthetic media, and found that the specific productivity in continuous culture was slightly higher than in batch cultures. Furthermore, Gordillo et al. ${ }^{9}$ also studied lipase production from Candida rugosa (ATCC 14830) in synthetic media and reported that the best operating mode tested was fedbatch, with controlled specific growth rate, which increased the productivity 10-fold, compared with batch operation. Thus, fedbatch experiments were performed using the three yeast strains. Figure 2 shows the time course of cell growth, reducing sugars consumption and lipase activity of the culture broth for the three yeasts.

Results showed, in general, higher cell growth (more than 1 log units), sugar consumption and lipase production (Fig. 2). The fed-batch culture strategy led to overall better results, especially for C. rugosa. 

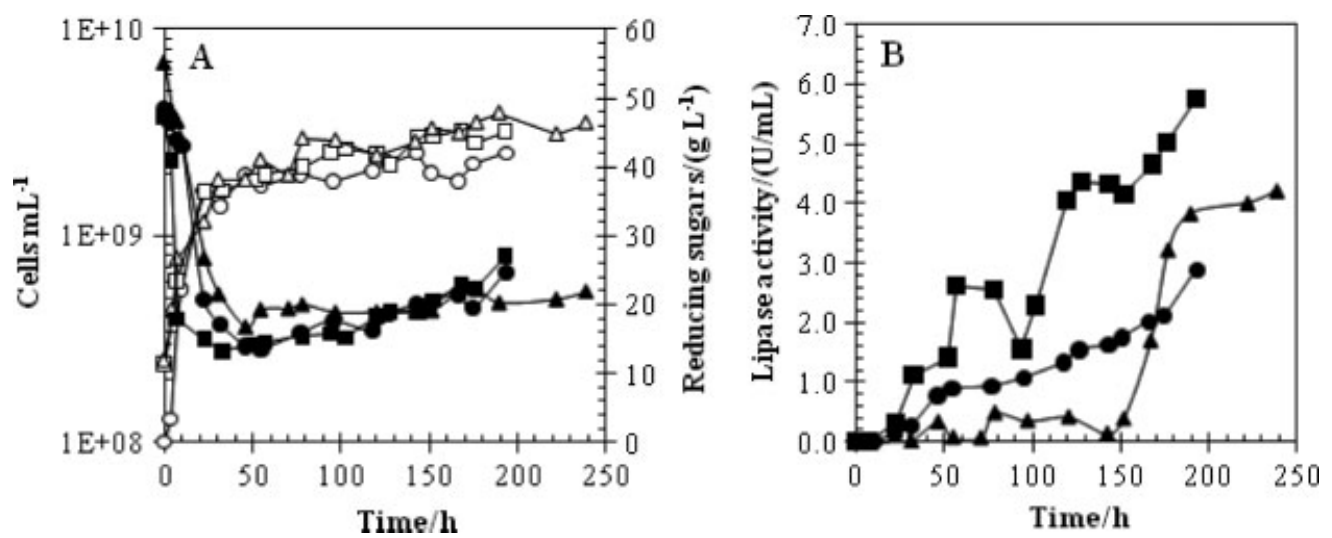

Figure 1. (A) Time course of cell growth (open symbols), reducing sugars consumption (closed symbols); and (B) lipase production, by C. cylindracea ( $\square$ ),

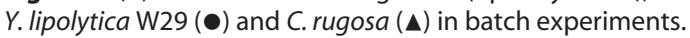
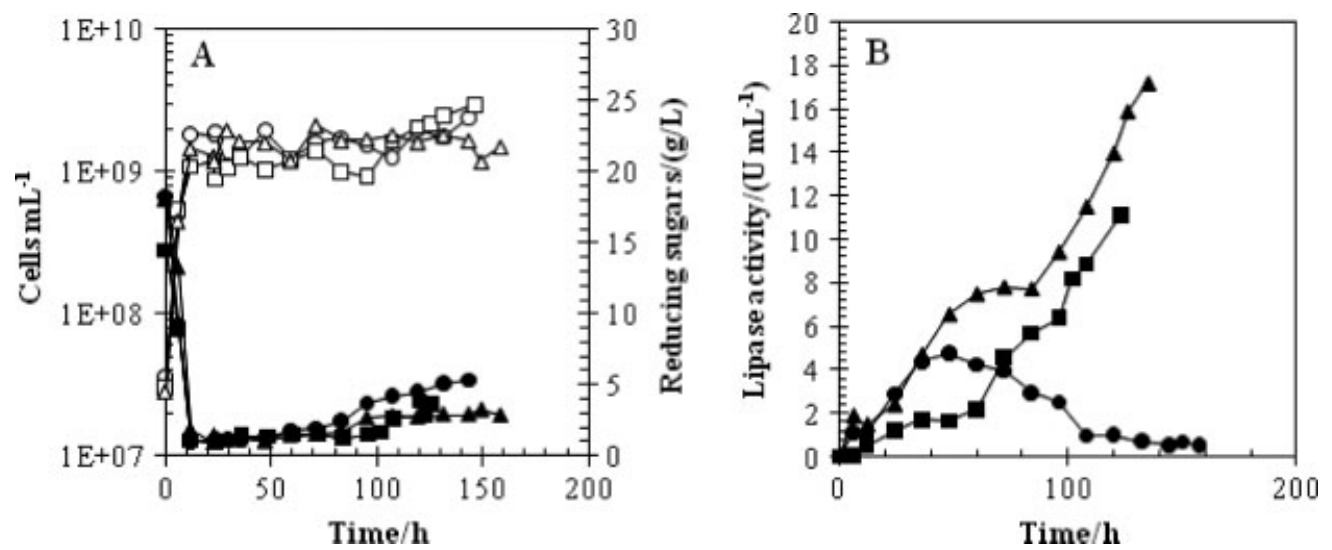

Figure 2. (A) Time course of cell growth (open symbols), reducing sugars consumption (closed symbols); and (B) lipase production, by C. cylindracea ( $\mathbf{\square})$, Y. lipolytica $(\bullet)$ and C. rugosa $(\boldsymbol{\Lambda})$ for fed-batch cultures.

The exponential phase ends after $12 \mathrm{~h}$, thus a long stationary phase occurred and higher values of lipase activity were obtained. In fact, a lipolytic activity of $17 \mathrm{U} \mathrm{mL}^{-1}$ was achieved by C. rugosa, the best lipase producer in these trials. C. cylindracea also reached good lipase activity values $\left(11 \mathrm{U} \mathrm{mL}^{-1}\right)$ in these conditions. Typical lipase production kinetics of $Y$. lipolytica, with a decay phase after achieving a maximum value of lipase activity $\left(5 \mathrm{U} \mathrm{mL}^{-1}\right)$, was observed (Fig. 2(B)). This kinetic of $Y$. lipolytica lipase production can be observed in several other works. ${ }^{17,18,20,22,23}$ A possible reason for this behaviour is the presence of protease (Fig. 3), which can be responsible for lipase breakdown. Comparing lipase (Fig. 2(B)) and protease (Fig. 3) production profiles by Y. lipolytica, an inverse relation between both is observed. Some authors ${ }^{23-25}$ also reported a sharp decrease in lipolytic activity caused by protease.

Global results of these experiments are summarized in Table 2 for COD, reducing sugars, phenolic compounds and lipids reduction. Besides the improvement of lipase production, the fedbatch approach enhanced the effluent degradation, since it led to good COD and lipids reduction, both higher than $50 \%$. C. rugosa achieved the highest value of lipase productivity $\left(130 \mathrm{UL}^{-1} \mathrm{~h}^{-1}\right)$, in parallel with highest lipids reduction (77\%). Freire et al..$^{24}$ observed the time course for lipase production and lipids consumption, by Penicillium restrictum, and found that the maximum lipolytic activity corresponded to the depletion of carbon source (lipids), which is in accordance with our results (Table 2 ). In these fed-batch

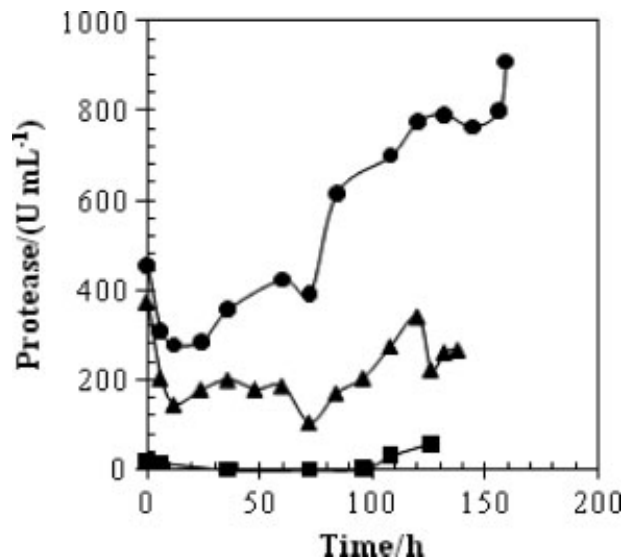

Figure 3. Time course of protease activity produced by C. cylindracea ( $\square)$, Y. lipolytica $(\bullet)$ and C. rugosa $(\boldsymbol{\Lambda})$, for fed-batch cultures.

experiments, $27 \%$ removal of phenolic compounds was reached using $C$. rugosa.

\section{CONCLUSIONS}

In conclusion, this study demonstrates that olive mill wastewaters are a competitive and valuable growth medium in fermentation processes with lipolytic microorganisms, since they allow 
Table 2. Overall results of effluent degradation (COD, reducing sugars, phenolic compounds and lipids consumption) obtained for fed-batch cultures

\begin{tabular}{|lccc|}
\hline Parameter & C. cylindracea & C. rugosa & Y. lipolytica \\
\hline COD/(\%) & 58 & 64 & 50 \\
Reducing sugars/(\%) & 52 & 66 & 54 \\
Phenolics/(\%) & 4 & 27 & 1 \\
Lipids/(\%) & 56 & 77 & 55 \\
\hline
\end{tabular}

significant production of lipase. The fed-batch strategy used in the reported work proved to be an efficient approach to enhance lipase production from OMW by Candida species, such as C. cylindracea and C. rugosa, and to reduce significantly the final organic load of the medium. C. rugosa CBS 2275 was the strain that presented the best performance using this mode of operation.

\section{ACKNOWLEDGEMENTS}

The authors acknowledge the financial support provided by 'Fundação para a Ciência e Tecnologia' (Project PTDC/AMB/ 69379/2006; Grant SFRH/BD/27915/2006).

\section{REFERENCES}

1 IOC (International Olive Oil Council) World Olive Oil Figures, http://www.internationaloliveoil.org/estaticos/view/131world-olive-oil-figures (accessed 5 November (2011)).

2 Vitolo $S$, Petarca $L$ and Bresci B, Treatment of olive oil industry wastes. Bioresource Technol 67:129-137 (1999).

3 Crognale S, D'Annibale A, Federici F, Fenice M, Quaratino D and Petruccioli M, Olive oil mill wastewater valorisation by fungi. J Chem Technol Biotechnol 81:1547-1555 (2006).

4 Federici F, Fava F, Kalogerakis $\mathrm{N}$ and Mantzavinos D, Valorisation of agro-industrial by-products, effluents and waste: concept, opportunities and the case of olive mill wastewaters.J Chem Technol Biotechnol 84:895-900 (2009).

5 Lanciotti R, Gianotti A, Baldi D, Angrisani R, Suzzi G and Mastrocola D, et al, Use of Yarrowia lipolytica strains for the treatment of olive mill wastewater. Bioresource Technol 96:317-322 (2005).

6 Asses N, Ayed L, Bouallagui H, Ben Rejeb I, Gargouri M and Hamdi M, Use of Geotrichum candidum for olive mill wastewater treatment in submerged and static culture. Bioresource Technol 100:2182-2188 (2009).

7 D'Annibale A, Sermanni G, Federici F and Petruccioli M, Olive-mill wastewaters: a promising substrate for microbial lipase production. Bioresource Technol 97:1828-1833 (2006).

8 Gonçalves C, Lopes M, Ferreira JP and Belo I, Biological treatment of olive mill wastewater by non-conventional yeasts. Bioresource Technol 100(WasteEng2008):3759-3763 (2009).
9 Gordillo MA, Montesinos JL, Casas C, Valero F, Lafuente J and Solà C, Improving lipase production from Candida rugosa by a biochemical engineering approach. Chem Phys Lipids 93:131 - 142 (1998).

10 Gordillo MA, Obradors N, Montesinos JL, Valero F, Lafuente J and Solà C, Stability studies and effect of the initial oleic acid concentration on lipase production by Candida rugosa lipase. App Microbiol Biotechnol 43:38-41 (1995).

11 Montesinos JL, Obradors N, Gordillo MA, Valero F, Lafuente J and Solà C, Effect of nitrogen sources in batch and continuous cultures to lipase production by Candida rugosa. Appl Biochem Biotechnol 59:25-37 (1996).

12 APHA, AWWA, WPCF, Standard Methods for the Examination of Water and Wastewater, 17th edn. Washington, DC (1989).

13 Gonçalves C, Rodriguez-Jasso RM, Gomes N, Teixeira JA and Belo I, Adaptation of dinitrosalicylic acid method to microtiter plates. Anal Method 2:2046-2048. (2010).

14 Neves L, Pereira MA, Mota M and Alves MM, Detection and quantification of long chain fatty acids in liquid and solid samples and its relevance to understand anaerobic digestion of lipids. Bioresource Technol 100:91-96 (2009).

15 AOAC International, Official Methods of Analysis, 18th edn. AOAC International, Gaithersburg, MD, Official Method 2003.05 (2007).

16 Gomes N, Gonçalves C, Garcia-Román M, Teixeira JA and Belo I, Optimization of a colorimetric assay for yeast lipase activity in complex systems. Anal Method DOI: 10.1039/COAY00680G (2011).

17 Eusébio A, Almeida-Vara E, Sena-Martins G, Mateus M and Cardoso Duarte J, Microbial treatment of olive oil wastewater. Proceedings International Workshop on Water in the Mediterranean Basin: Resources and Sustainable Development 210-217 (2002).

18 Lopes M, Gomes N, Gonçalves C, Coelho MAZ, Mota M and Belo I, Yarrowia lipolytica lipase production enhanced by increased air pressure. Lett Appl Microbiol 46:255-260 (2008).

19 Tziotzios G, Michailakis S and Vayenas DV, Aerobic biological treatment of olive mill wastewater by olive pulp bacteria. Int Biodeter Biodegr 60:209-214 (2007).

20 Lopes M, Araújo C, Aguedo M, Gomes N, Gonçalves C and Teixeira JA, et al, The use of olive mill wastewater by wild type Yarrowia lipolytica strains: medium supplementation and surfactant presence effect. J Chem Technol Biotechnol 84:533-537 (2009).

21 Aouidi F, Gannoun H, Othman NB, Ayed L and Hamdi M, Improvement of fermentative decolorization of olive mill wastewater by Lactobacillus paracasei by cheese whey's addition. Process Biochem 44:597-601 (2009).

22 Gomes N, Teixeira JA and Belo I, The use of methyl ricinoleate in lactone production by Yarrowia lipolytica: aspects of bioprocess operation that influence the overall performance. Biocatal Biotransform 28:227-234 (2010).

23 Pereira-Meirelles FV, Rocha-Leão MH and Sant Anna GL Jr, A stable lipase from Candida lipolytica: cultivation conditions and crude enzyme characteristics. Appl Biochem Biotechnol 63-65:73-85 (1997).

24 Freire DM, Teles EMF, Bon EPS and Sant'Anna GL, Lipase production by Penicillium restrictum in a bench-scale fermenter: media composition, agitation and aeration. Appl Biochem Biotechnol 63-65:409-421 (1997).

25 Gombert AK, Pinto AL, Castilho LR and Freire DMG, Lipase production by Penicillium restrictum in solid-state fermentation using babassu oil cake as substrate. Process Biochem 35:85-90 (1999). 